\title{
Using GIS and photogrammetry for assessing solar photovoltaic potential on Flat Roofs in urban area case of the city of Ben Guerir / Morocco
}

\author{
H. Saadaoui ${ }^{1,2 *}$, A. Ghennioui ${ }^{2}$, B. Ikken $^{3}$, H. Rhinane ${ }^{1}$, M. Maanan ${ }^{1}$ \\ 1 Earth Sciences Department, Faculty of Sciences Ain Chock, University Hassan II, Casablanca, Morocco. \\ 2 Institut de Recherche en Energie Solaire et Energies Nouvelles IRESEN, Green Energy Park Benguerir, Morocco \\ 3 Institut de Recherche en Energie Solaire et Energies Nouvelles IRESEN, Green Energy Park Rabat, Morocco \\ * Corresponding authors: hachem.saadaoui@gmail.com
}

KEY WORDS: Photovoltaic Potential, Solar radiation, GIS, Solar Analyst, DSM, photogrammetric restitution.

\section{ABSTRACT:}

Renewable energy sources are at the forefront of political discussions around the world because of the scarcity of fossil fuels and climate change caused by the accumulation of greenhouse gases. By 2030, Morocco will cover 52\% of these energy needs through renewable energies, in order to preserve the environment (COP 22). This paper aims to estimate the potential of photovoltaic solar energy from flat roofs in the city of Ben Guerir, Morocco using remote sensing and GIS data. To achieve this goal, vector orthophoto resulting from the photogrammetric restitution acquired in 2015 were used to generate a 3D model (DSM). The annual solar irradiation is calculated by the analyser of the solar tool. Each roof is calculated based on algorithms for the most common solar panel technologies (mono-si and poly-si). The applicability of this methodology has been demonstrated in the urban area of Benguerir, Morocco, and can be widespread in any other region of the world. The results obtained for a total roofing surface of $135 \mathrm{Ha}$, i.e. more than $345 \mathrm{Gwh}$ of electricity annually generate. For an average roof of $60 \mathrm{~m}^{2}$ that could supply 5 to 6 households; A planned investment between 118,218 and 167,296 DH, and an annual maintenance charge of $2 \%$. This study may be an initial assessment of solar potential in the city, which can be used to support the management decision regarding investment in the urban solar system.

\section{INTRODUCTION}

Conventional carbon-based energy production around the world is of growing concern. The stakes are many: increasing atmospheric concentrations of carbon dioxide from greenhouse gas emissions, environmental safety of energy production techniques, volatility of energy prices and depletion of fuel Reserves. Energy production remains one of the largest contributors to carbon dioxide emissions worldwide. (Nguyen and Pearce 2010, Choi, al.). It is imperative that all of humanity mobilize to participate in efforts to control and effectively manage these impacts.

For this reason, that the implementation of renewable energy has emerged as an essential component of energy policy for governments at the national, regional and local levels to reduce global warming. Onboard energy production, in particular photovoltaic solar energy, is emerged as an essential element of political responses in terms of renewable energies (Ordóñez, Jadraque, Alegre \& Martinez, 2010).

Therefore, country's policy tends to apply strategic guidelines to improve energy efficiency based on renewable energy.

Solar energy is one of the most promising and sustainable energy sources for its easy accessibility. In recent years, the technology that uses the PV (photovoltaic) effect for the production of electrical energy has progressed enormously (Lewis NS,2010).

Solar photovoltaic Energy (PV) is stone recognized as abundant, clean and safe source. Its deployment in urban areas and especially on rooftops has been strongly supported by governments around the world, whose many advantages are the modular and silent nature and avoiding loss of transmission and distribution to As electricity is generated (Ruther et al., 2008)
This research aims to achieve the Goal 7; one of the 17 goals set by the United Nations Economic and Social Council, which aims to guarantee access to reliable, sustainable and modern energy services to everyone and at an affordable cost.

Like all non-oil producing countries, Morocco devotes a large budget to the energy sector. Faced with this situation and in order to satisfy its population of approximately 34 million inhabitants in energy, Morocco adopted in 2009 an ambitious strategy of supply of equipment and reduction of $15 \%$ of the energy consumption in 2020 by using renewable energies. For example, Morocco has announced a $\$ 9$ billion solar energy project that, according to officials, will account for $38 \%$ of installed electricity generation in North Africa by 2020. The project will involve five solar energy productions stations in Morocco Ouarzazate, Tarfaya, Boujdour, Laayoune, and Ain Beni Mahtar (chosen for its many sunny days) will produce 2,000 megawatts of electricity by 2020 . With the increase of energy demand and the challenge of globalization and global warning, the Moroccan solar energy project is in line with the international trend by producing renewable energy, especially solar energy.

This strategy has raised Morocco in the top ranks of attractive countries for renewables energy.

Despite this position of Morocco, the culture of using solar energy for the sustainable development of urban areas is not yet a priority for decision makers. The majority of Moroccan cities continue to depend on conventional energy sources (fuels, hydroelectric power). In these cities, we notice that some buildings and residential sectors use photovoltaic (PV) energy produced by solar irradiation for water heating and not for the production of electricity.

In this context and given its wide scientific potential. Morocco is characterized by intense solar irradiation with an average of 5.3 
$\mathrm{kWh} / \mathrm{m} 2$ under annual sunshine ranging from $2700 \mathrm{~h}$ in the north to about $3500 \mathrm{~h}$ in the south.

In 2017, the total installed capacity of the Office's electricity generation fleet (ONE) stood at 8,820.194 MW, compared to $8,261,694 \mathrm{MW}$ in $2016.33 .67 \%$ of the installed capacity is from a renewable source. (Source ONE Morocco) (fig.1 and 2).

Morocco recently announced an ambitious plan for the development of integrated solar projects with combined cycle units (ONE Morocco).

The project would:

Produce $52 \%$ of energy needs with renewable energies by 2030, thus preserving the environment (COP 22).

Provide access to energy for the general population at an affordable and competitive price.

Achieve sustainable development through the promotion of renewable energies.

Promote productivity, competitiveness, and strengthen regional integration by opening to Euro-Mediterranean energy markets and harmonizing energy legislation.

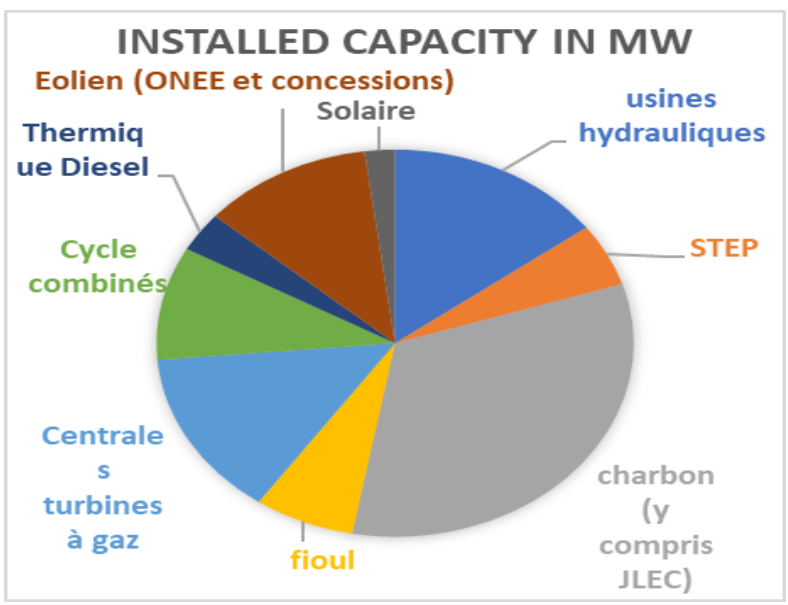

Figure 1. Installed power in MW by ONE in Morocco (Source http://www.one.org.ma)

\section{Electric production in $\mathrm{GWh}$}

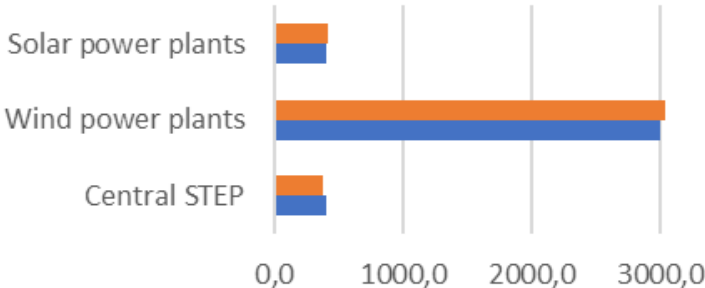

- Production éléctrique en GWh 2017

- Production éléctrique en GWh 2016

Figure 2. Electric production in GWh by ONE in Morocco (source http://www.one.org.ma)
While on-board power generation typically includes a variety of energy technologies, rooftop solar PV has become a dominant integrated renewable energy option.

With a supportive policy, effective planning and implementation, rooftop solar photovoltaic power generation will permanently change the dynamics of electricity supply and generation and will inaugurate new market paradigm. As a new and innovative energy paradigm, it will redefine new roles for existing players in the sector, perhaps the disappearance of some existing or mature business models, and open new spaces for new players in the sector. An orderly development of the sector that fully exploits the benefits of sustainable development can only be achieved if there is sufficient information on its impact, benefits, limitations and potential. As an emerging sector in Morocco, insufficient attention has been paid to quantifying the potential of solar PV on the roof, in urban areas particularly, where market penetration is expected.

The main objective of this study is to evaluate and quantify PV technic potential on the flat roof in Benguerir, Morocco. Using solar radiation tools and the existing PV equation. Knowing the amount of incident solar radiation and optimal roof areas to capture this energy, the solar potential of any roof plane can be easily calculated.

Many studies have been developed and carried out to estimate, calculate and quantify the amount of energy that can be collected using solar system technology according to the appropriate free rooftop area in urban areas, several studies have also expanded to potential solar facades and other vertical surfaces. These studies range from simple multipliers of total building space to methods using complex geographic information systems (GIS) or threedimensional models (3-D). Constant value selection, manual selection and GIS-based methods are the three main methods commonly used (Meluis et al., 2013).

Implementing this approach using Solar Analyst Extension requires a $3 \mathrm{D}$ model of the study area, all previous studies referenced in this work are with 3D building model based on LIDAR data. Aerial LIDAR currently offers the ability to produce detailed and accurate 3D city models (T. Santos, 2014). As a result, airborne LIDAR has become an accurate and cost-effective alternative to conventional technologies for creating altimetry data with vertical accuracies ranging from 0.15 to $1 \mathrm{~m}$.

However, the LIDAR data are so expensive and do not cover our study area, so we had to create and prepare our buildings 3D model in the study area using digitized maps obtained by photogrammetric rendering of Ortho-Photo images considering the altitude of the structure.

It is relevant to point out that, according to the literature (eg, Izquierdo et al., 2008), the solar potential can be characterized in different hierarchical classes: the total amount of energy received from the sun is the physical potential, while the geographic potential is limited to where this energy can be captured; the solar technical potential takes into account the technical characteristics of the equipment, including its performances and its losses in order to determine the power generated by the PV modules.

This work focuses mainly on the technical solar potential since it considers mutual shades effect between buildings as well as the performance of the modules themselves, via the PV conversion efficiency, including the minimum surface restriction. for viable photovoltaic systems. (T. Santos, 2014). 


\section{STUDY AREA}

The city of Benguerir, located north of the touristic city of Marrakech, was chosen for this study. With a population of 88,626 (RGPH 2014) It is located at $32.23 \mathrm{~N},-7.95 \mathrm{~W}$ and with a surface of $17.66 \mathrm{Km}^{2}$. The city is often described as an environment with a stepped prevailing climate, similar to desert climates, with hot days, and cold nights. Minimum temperatures below the threshold of $0^{\circ} \mathrm{C}$ and temperatures above $45.8^{\circ} \mathrm{C}$ (IRESEN High Precision Meteorological Station in Ben Guerir, Morocco 2017). The great plains and hills of Benguerir dominate the physiography of the city. With an annual average of $30 \mathrm{~mm}$ of precipitation per year (IRESEN High Precision Meteorological Station in Ben Guerir, Morocco 2017). Benguerir was chosen to be used to ensure the most reliable data to estimate solar irradiation (Fig. 3). The limits were defined by the availability of photogrammetric rendering data. The study area includes two structures, one characterized by two main types of buildings, residential and industrial. The residential consists of business buildings and administrative building. And where OCP is located, consists mainly of schools, villas and research centers.

\section{MATERIALS AND METHODS}

The data are the most important element in a GIS project, in this study all the data used were extracted from the vectorized orthophotomap of Benguerir city using photogrammetric restitution techniques obtained from the urban agency from KalaaSraghna. Vectorized data is saved in a CAD file, then integration into a GIS database by converting the CAD file to a geodatabase and the assigning coordinate system (Conformal Lambert Zone 1) was necessary for better data manipulation. A vectorized geodatabase considered as the best substitute for LIDAR data, characterized by high accuracy and also containing an altimetric attribute of all digitized structures.

To evaluate the photovoltaic solar potential on flat roofs in urban areas, we use a hierarchical approach that is widely used in the literature, which includes three steps:

- Producing a 3D model of buildings from data extracted from the restitution photogrammetric of the city of Benguerir, this step includes the creation of the model of digital elevation from $\mathrm{Z}$ points covering the study area.

- Generating solar irradiation using Solar Analyst tools, which derive directly and diffuse solar irradiation scattered over the study area throughout the year of 2017.

- Calculating the installable photovoltaic power, the potential of photovoltaic production and the cost of investing adequate roofing on the study area according to the solar irradiation already calculated and technical parameters.

Footprint Construction and $\mathrm{Z}$ points are extracted from the vectorized Geodatabase, applying a mask on the study area, deleting all other layers, and exporting the results to a new shapefile. Two shapefiles were obtained, one for the $\mathrm{Z}$ points containing a scatter plot with an altimetric attribute covering the study area, the second for the building footprint, containing the Zone, Type and Altitude attributes of the buildings. (Fig. 5)

\subsection{Creating the DSM from the vectorized geodatabase}

The DSM (Digital Surface Model) is a three-dimensional representation of building variation and topography required for input into Solar Analyst tools. The generation of DSM has been executed in important steps:

- Calculating the TIN from the $\mathrm{Z}$ shape file and converting it to DEM with an accuracy of 1 meter.

\section{Study Area of Benguerir, Morocco}
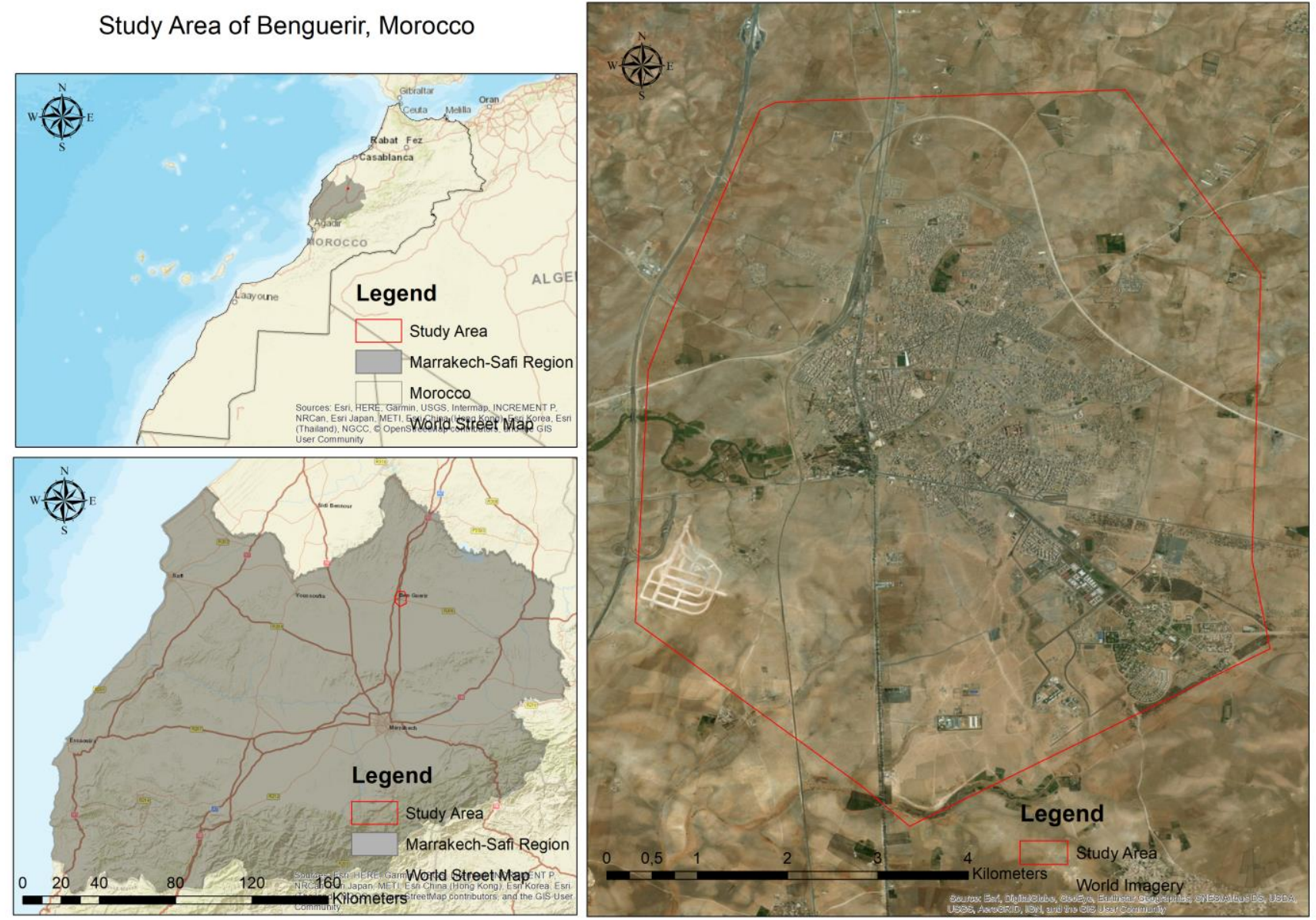

Figure 3. Study Area for Solar potential. 
- Applying a bilinear interpolation to increase the raster resolution to obtain more precision, the final DEM has a precision of $0.5 \mathrm{~m}$.

- Converting the Imprint into a raster by assigning the elevation attribute as a pixel value.

- Using the raster calculator, the elevation of the buildings was obtained by applying a simplified equation (1).

Syntax VBScript:

Con ((roof_raster) - $(\mathrm{MNT})>0$, (roof_raster) - (MNT),

(roof_raster) $-(\mathrm{MNT})<0,0) \quad(1)$

- DSM was finally generated by combining the raster result with the final DEM, with a precision of $0.5 \mathrm{~m}$. (Fig. 5)

\subsection{Calculating the solar irradiation in $\mathrm{wh} / \mathrm{m}^{2} / \mathbf{y r}$}

The Solar Radiation Zone tool is used to calculate sunshine across an entire landscape. The calculations are repeated for each location in the input DSM, producing sunshine maps for an entire geographic area. The calculation is based on the position of the sun and the direct beam irradiation; while the second is based on the atmosphere and calculates diffuse solar irradiation. Reflected solar irradiation is excluded from the calculation (Minghetti et al., 2011, Africani et al., 2013). The latitude of the study area (units: decimal degree, positive for the northern hemisphere and negative for the southern hemisphere) is used in calculations such as solar declination and solar position (Area solar radiation tool). The insolation raster has been calculated with a precision similar to the input raster $(0.5 \mathrm{~m})$, the output raster generated is a floating point and has a unit of watts per square meter per year ( $\mathrm{Wh} / \mathrm{m}^{2} /$ year).

The mask extracted using the Buildings Footprint layer was applied to the solar irradiation pattern to extract the solar irradiation value on the rooftops in the study area. (Fig. 6)

On the other hand, this work proposes a detailed analysis of the solar potential, namely for each roof of the buildings:

- A fine analysis of useful roof parts.

- Evaluation of the solar photovoltaic potential production.

- Calculation of energy and economic indicators.

This evaluation is performed according to standard models of solar collectors. The use of GIS tools is very useful for systematizing and automating calculations.

\subsection{Identification of useful surfaces}

The raw raster layer of irradiation shows a great variability of irradiation from one pixel to another on some roofs. This is particularly the case for partially shaded roofs. The average irradiation may be low overall, while a whole part of the unshaded roof is favorable for a solar installation.

Consequently, it will be necessary to highlight these useful surfaces (exploitable or productive), on which will be calculated the PV potentials. (Fig. 7)

The figure below illustrates these useful surfaces in red an irregular shape. These parts are very useful for approximately delineating, as part of a preliminary analysis, the potential areas to install solar panels.

This analysis consists, from a raw digital file of the annual solar irradiation, to select the eligible pixels according to given criteria, then to agglomerate and vectorize them.

The criteria selected are the following:

- Pixels whose minimum irradiation of $1000 \mathrm{kWh} / \mathrm{m} 2$ / year. This threshold is relatively mild, avoiding at this stage to be too discriminating. According to the results of a sensitivity analysis, it makes it possible to select the useful portions of the surface that are not significantly obstructed by nearby obstacles located on well oriented east - south - west surfaces.

- Pixels located beyond $1 \mathrm{~m}$ from the edge of the surfaces are not tacked into account as an edge effects (discontinuity) and knowing that a margin is generally necessary between the edges of roofs / surfaces and solar installations (supervising).

-Useful surface areas $>5 \mathrm{~m} 2$ : the agglomeration of the pixels selected according to the first two criteria generates a large number of very small unusable surfaces, this threshold makes it possible to select surfaces so the installations become possible (starting with the individual houses). (Fig. 5)

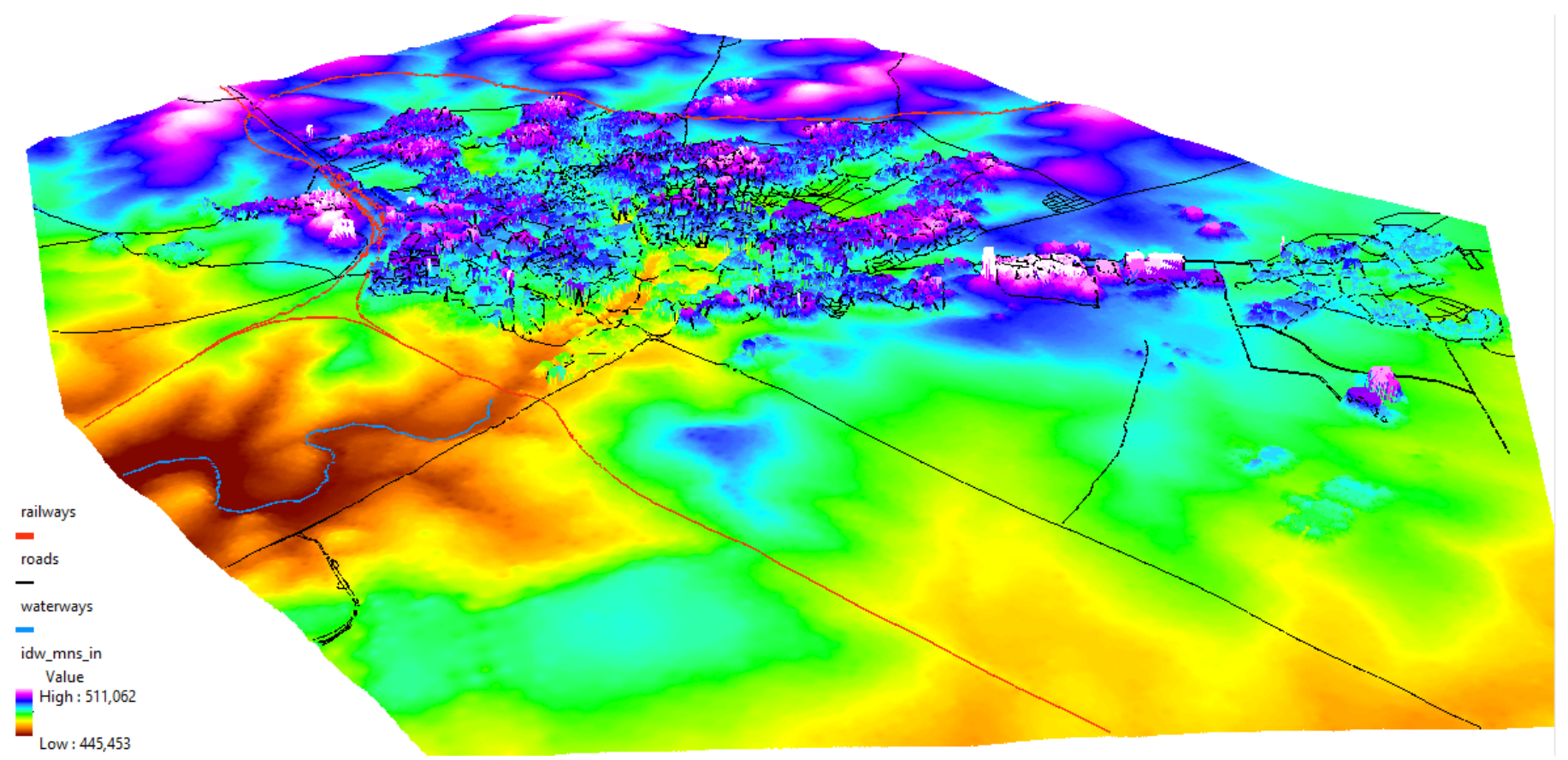

Figure 4. Generated DSM of the Benguerir. 
The International Archives of the Photogrammetry, Remote Sensing and Spatial Information Sciences, Volume XLII-4/W12, 2019 5th International Conference on Geoinformation Science - GeoAdvances 2018, 10-11 October 2018, Casablanca, Morocco

\section{1-Post-Treatment}

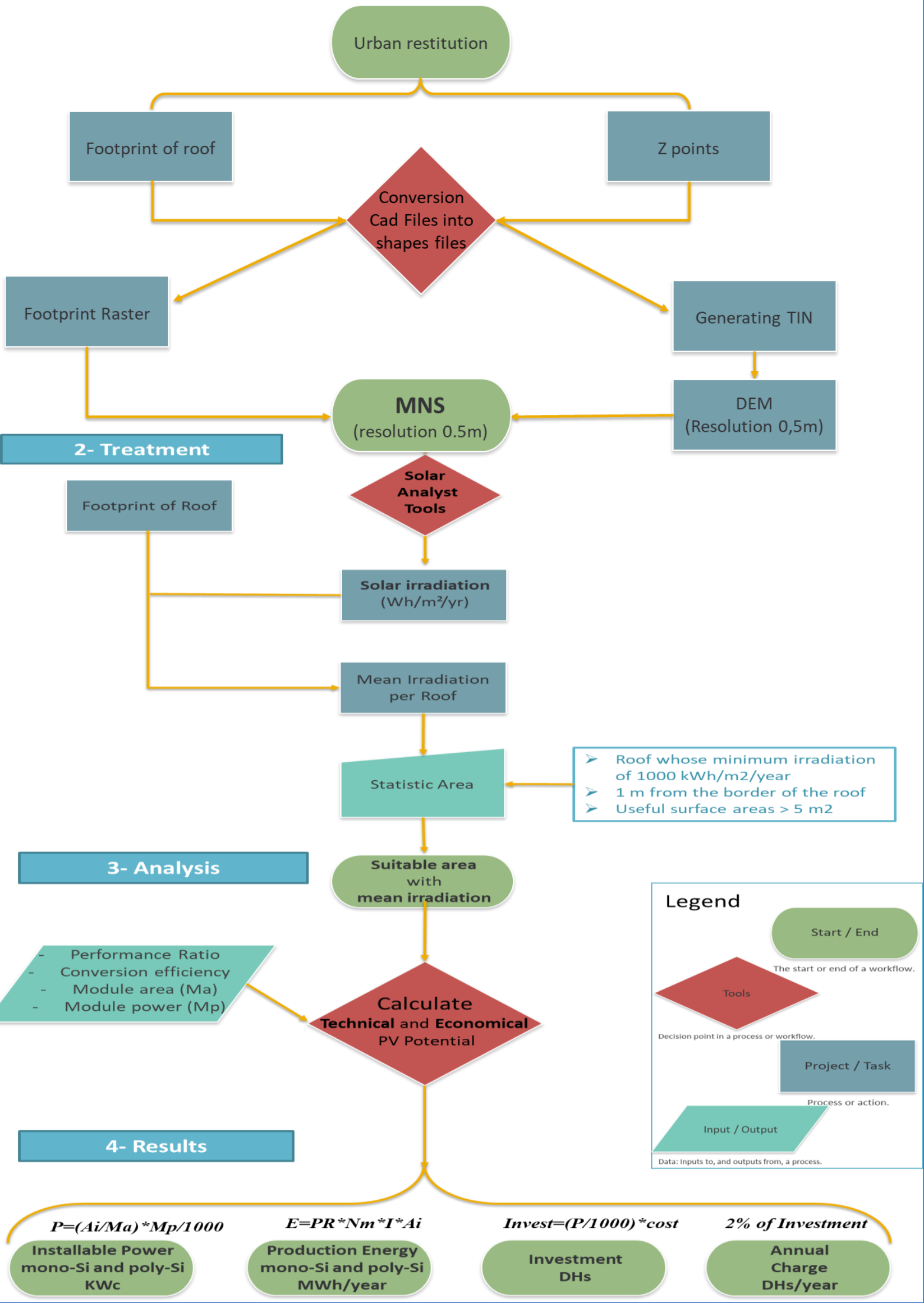

Figure 5. Flowchart for calculating PV potential for this study 
The International Archives of the Photogrammetry, Remote Sensing and Spatial Information Sciences, Volume XLII-4/W12, 2019 5th International Conference on Geoinformation Science - GeoAdvances 2018, 10-11 October 2018, Casablanca, Morocco

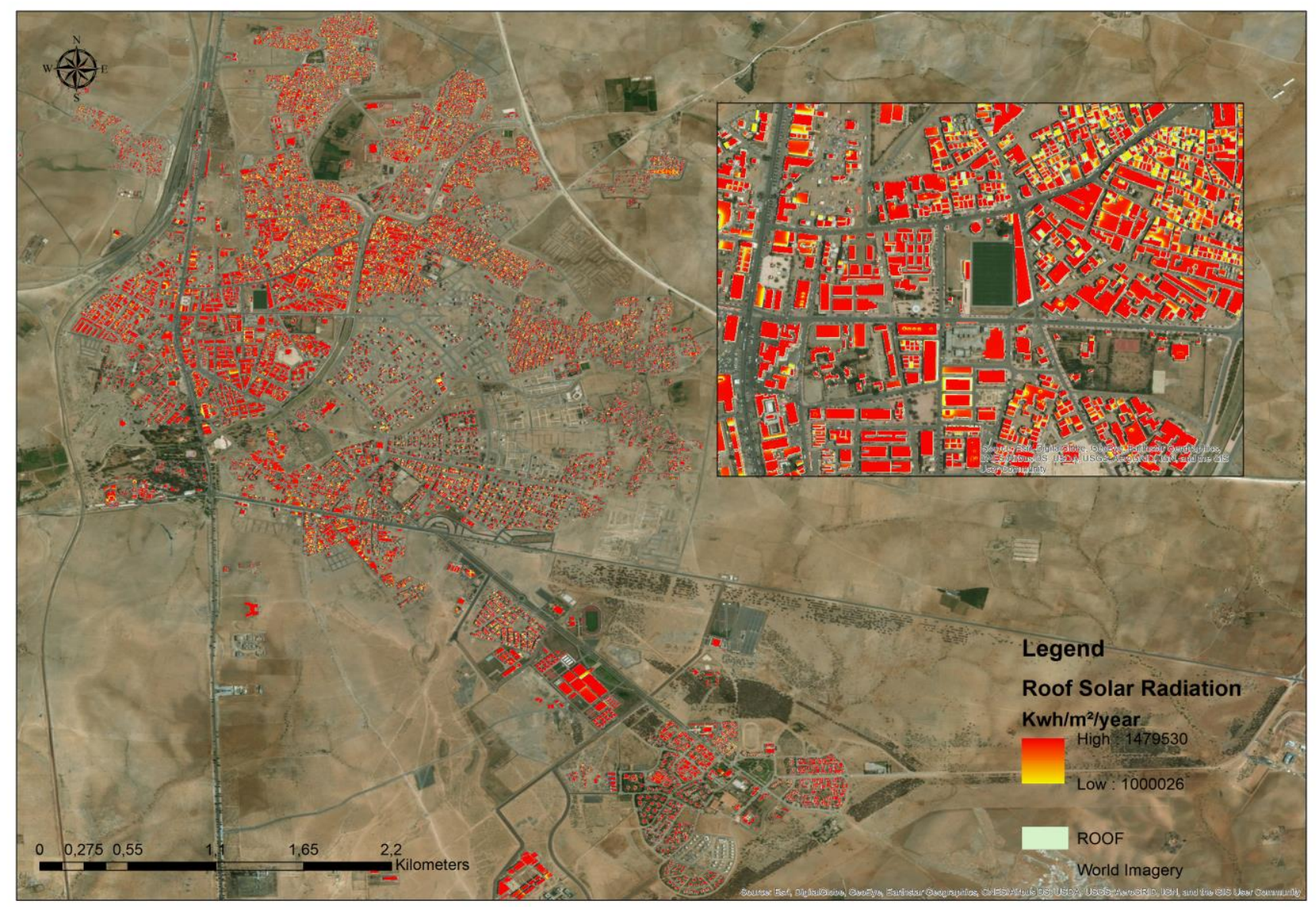

Figure 6. Solar irradiation on flat roof of Benguerir.

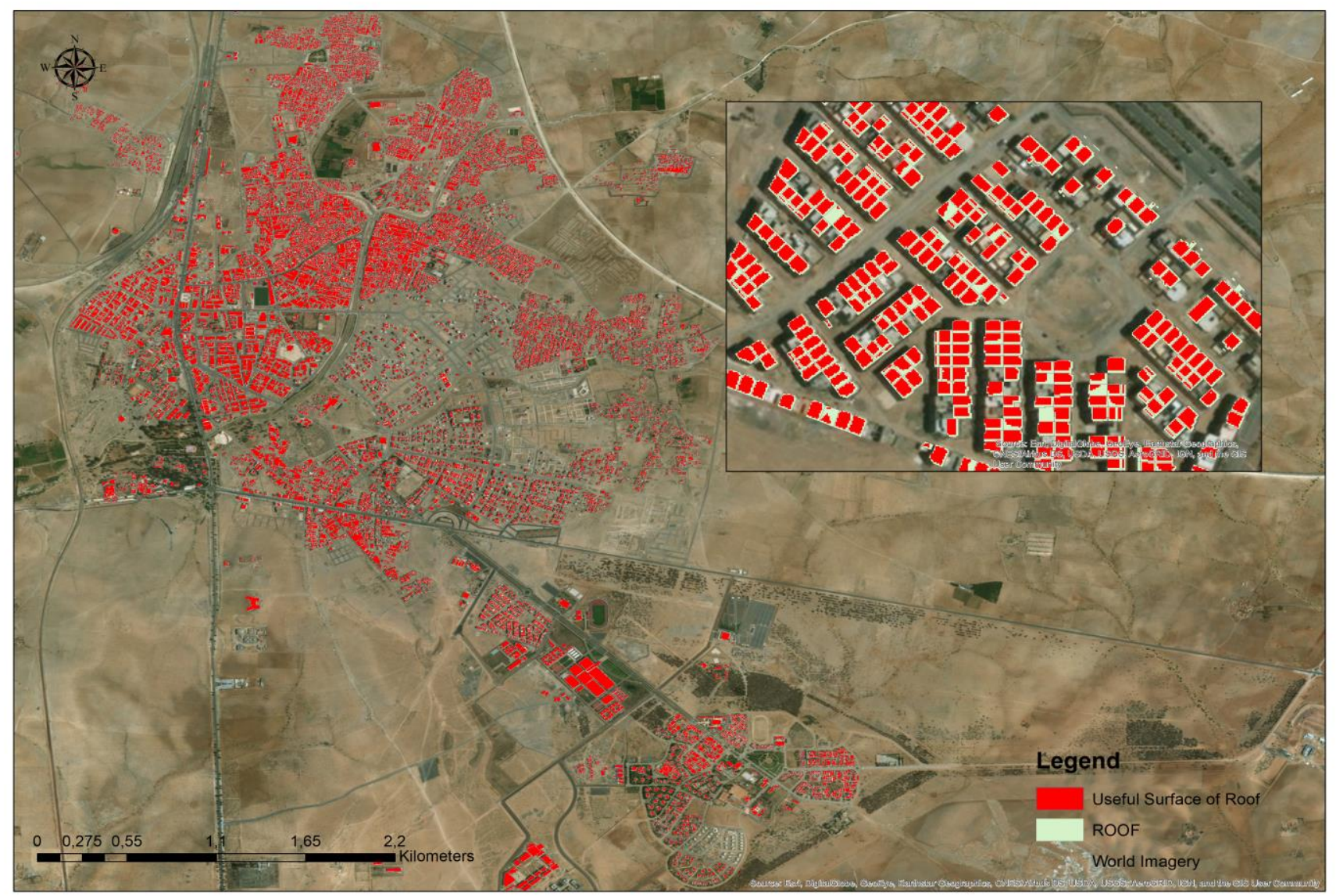

Figure 7. Example of useful surface compared to basic surfaces in Benguerir. 


\subsection{Calculation of photovoltaic solar potential on rooftops}

To calculate the photovoltaic potential of roofs, the derived raster from the previous step containing solar radiation on roofs in watt hour per square meter per year $\left(\mathrm{Wh} / \mathrm{m}^{2} / \mathrm{yr}\right.$ ) was converted into kilowatt hour per square meter per year $\left(\mathrm{kwh} / \mathrm{m}^{2} / \mathrm{yr}\right)$.

Although solar radiation is one of the main factors in calculating photovoltaic potential generation, other factors like technology, orientation and maintenance play important roles as well. Many web-based GIS solar tools use simplified formulas to assess PV potential. In most cases, calculating the PV potential requires a consideration of different output capacities: the type of the panels or system in place. The equation used to calculate the technical photovoltaic potential consider two technical parameters (Conversion efficiency, performance ratio), geographical one (Area) and the annual solar radiation in kilowatt hour per square meter.

From the actual area of the useful roof parts and the corresponding panels, it is possible to calculate the total annual electricity production for representative sensors according to the two current technologies on the market:

- Standard yield (Polycrystalline).

- High performance (Monocrystalline).

The electric potential is expressed in two ways: - in peak power (2), according to the data of the manufacturers of the panels type selected according to the formula applied:

$$
\mathrm{P}(\mathrm{KWc})=\left(\mathrm{Ai}\left(\mathrm{m}^{2}\right) / \mathrm{Ma}\left(\mathrm{m}^{2}\right)\right) \times \mathrm{Mp}(\mathrm{Wc}) / 1000
$$

- in energy, according to the performance ratio ('PR') and the efficiency of the sensor type and according to the gross annual irradiation and the useful surface, according to the formula applied (3):

$$
\mathrm{E}(\mathrm{kWh} / \text { year })=\mathrm{PR} \times \mathrm{Nm} \times \mathrm{I}(\mathrm{kWh} / \text { year }) \times \mathrm{Ai}\left(\mathrm{m}^{2}\right)
$$

Where $\mathrm{Ai}=$ The suitable area in the Roofs for PV Installation.

$\mathrm{Nm}=$ Conversion efficiency of the panel System.

$\operatorname{Pr}=$ Performance Ratio0

$\mathrm{I}=$ the annual Solar Radiation in $\mathrm{Kwh} / \mathrm{m}^{2} / \mathrm{yr}$.

$\mathrm{Ma}=$ Module area in $\mathrm{m}^{2}$.

$\mathrm{Mp}=$ Module power in $\mathrm{Wc}$.

\begin{tabular}{|l|l|l|}
\hline technology & monocrystalline & polycrystalline \\
\hline classification & Silicium $(\mathrm{c}-\mathrm{Si})$ & Silicium $(\mathrm{mc}-\mathrm{Si})$ \\
\hline Dimension $(\mathrm{mm})$ & $1046 * 1559 * 35$ & $1650 * 992 * 35$ \\
\hline Power $(\mathrm{Wc})$ & 345 & 265 \\
\hline Yield $(\%)$ & 21,5 & 16,19 \\
\hline Mean PR (\%) & 83 & 79 \\
\hline $\begin{array}{l}\text { surface per module } \\
\left(\mathrm{m}^{2}\right)\end{array}$ & 1,63 & 1,63 \\
\hline $\begin{array}{l}\text { brand } \\
\text { investment }(\mathrm{DHs} / \mathrm{Wc})\end{array}$ & $\begin{array}{l}\text { Sunpower } \\
\text { X21-345 }\end{array}$ & $\begin{array}{l}\text { Trinasolar } \\
\text { TMS-265PD05 }\end{array}$ \\
\hline
\end{tabular}

Table. 1: PV technologies and features

The Pr is defined as the ratio of on-field performance of the system to its performance in standard test condition of 1000 $\mathrm{W} / \mathrm{m} 2$ global insolation, $25^{\circ} \mathrm{C}$ module temperature and 1.5 air mass (Ramachandra et al., 2011). It considers the overall effect of losses on the output of the system. Losses can be due to inverter inefficiency, direct current (DC) to alternate current (AC) conversion, soiling or snow and incomplete use of irradiance by reflector system. Mostly available PV systems have $\operatorname{Pr}$ in between 0.66 and 0.85 (Turkenberg, 2004) There is several types of panels systems, in this work we choose the most common two types of photovoltaic panels existed in the market, Monocrystalline and polycrystalline. The $\mathbf{A i}$ is the suitable area in the Roofs correspond to the total area of the roof. (Fig. 8 and 9)

The average of technical photovoltaic potential on each roof is calculated using zonal statistic table tool, the raster from the previous step used as input raster holding the values of technical PV potential and the building footprints as dataset defining the border of each roof. (Fig. 5)

\subsection{Economic indicators}

In addition to sensor surfaces and electricity production potentials, the economic indicator is calculated by usable area and by type of technology:

- Investment costs (DHs).

- Annual operating and maintenance charges, estimate $2 \%$ of the investment costs including: general maintenance of the PV installation, cleaning of the panels, remote monitoring, service and maintenance of the inverter, possibly service contract, provisions for the replacement of inverters (DHs / year). (Tab. 1)

\section{Results AND Discussion}

The application of this methodology in the study area shows a significant PV potential on the Benguerir rooftops, the matrix maps derived from the equations described above are classified by PV potential values in four classes, and illustrates a significant geographical variation of the total PV potential per roof, this may be due to different factors:

- Roof area: Buildings with a large free area on the roof, the PV system can be installed efficiently and can collect the greatest potential in the study area.

- Impact of the shadow: the variation of buildings height influences the PV potential, the buildings with high altitude can obstruct the direct radiation. (The altitude of the trees is not considered in this study because of the height of the buildings which exceed the heights of the trees)

- PV system technology used: The technical PV potential is calculated for the two most common types of silicon panels (monocrystalline mono-Si and polycrystalline Poly-Si), the result shows the highest PV potential values for Mono-Si panel as Poly-Si, because of the technical characteristics of each type of panel (ex: conversion efficiency $16.19 \%$ for poly-Si and $21.5 \%$ for mono-Si)

- Orientation of buildings, the topography of the study area and other factors may influence the amount of PV potential that can be generated. (Fig. 8,9)

The PV potential attribute table is classified by roof area into nine classes, the average of the PV technical potential (power and energy produced) is calculated for each class. Then, the monetary value of the PV potential (investment and annual maintenance) is estimated. (Tab. 2)

The results show that for the sum of 17392 roofs with a total area of more than $135 \mathrm{Ha}$ can: 
- Install a power of $286 \mathrm{MWc}$ for Monocrystalline systems against $219 \mathrm{MWc}$ for polycrystalline systems.

- Generate an annual electricity production of $345 \mathrm{GWh}$ for Monocrystalline systems against $247 \mathrm{GWh}$ for polycrystalline systems.

- A cost of 3.7 billion dirhams of to invest on installation of Monocrystalline systems against 2.6 billion dirhams for polycrystalline systems, and an annual maintenance charge ranging from 52 to 74 million dirhams.

Knowing that the average consumption per person of electricity in Morocco is about 1013 (Kwh), the photovoltaic potential can be generated by the roof having a surface ranging from 100 to 200 meters being able to satisfy the electrical consumption of 20 people for the panels Poly$\mathrm{Si}$ and 23 people for Mono-Si panels in every building.

It is important to mention that these indicators, calculated systematically on all the useful roofs of Benguerir, are given as an indication with a margin of uncertainty that can be significant (the useful surfaces do not necessarily correspond to the effective footprint of the solar panels), and in any case, a detailed calculation will have to be done case by case, with specialized software, for installations in the pre-project phase.

\section{CONCLUSION}

The solar GIS tool could be implemented to develop the Benguerir city-wide solar cadaster, thanks to the computing powers and the systematic and automated spatial processing specific to GIS, while keeping a high precision of analysis (pixel of $0.5 \mathrm{~m}$ ) required for a fine analysis of the solar irradiation on the roofs. The methodology presented in this paper evaluates the technical PV potential in urban settings using vectorized orthophoto to generate a 3D model. The study area covers approximately 17,392 buildings containing residential, administrative and industrial buildings.

The results show that a significant annual PV potential can be generated in buildings roofs, ranging from $247 \mathrm{Gwh}$ to $345 \mathrm{Gwh}$, which can meet the power consumption needs of more than 500,000 people in the study area. The results illustrate and classify roofs by degree of suitability for solar system installation and give an overall idea of the monetary value that can be invested per building using the solar system.

The applications of the results of solar cadaster are multiple in the context of the territorial energy planning: implications on the real estate market by redefining the value of the buildings compared to their solar energy potential on the roof, levers of actions for the communities to Increase the installation of solar panels through different measures and actions.

Solar energy planning at the urban scale will require the use of other indicators that can be developed on the basis of Solar Cadaster and other information on the available built fabric:

- Shader factor in raster mode (ratio between the image including shading). This information is very useful in the perspective of installing PV collectors.

- Extraction of roof pieces with an annual irradiation higher than $1000 \mathrm{kWh} / \mathrm{m} 2$ (potential surfaces for the installation of collectors). The calculation of the surface of these pieces makes it possible to retain those which have a minimal surface required for the different technologies.

- Overall statistics on the quarter of the total areas per irradiation tranche

- Evaluation of photovoltaic energy production potentials, irradiation information with used information and characteristics of buildings. Environmental balance analysis related to the installation of solar collectors (avoided GHG emissions).

Finally, given the relatively rapid evolution of the built fabric in Benguerir, a periodic update of the solar cadaster, as well as basic data (LIDAR and vector model of roofs) must be considered in order to consider the solar potential of recent constructions with more precision.

More complete 3D city models can also be developed, which include the effects of trees, urban infrastructure, socio-demographic statistics and energy consumption to better reflect the properties of various intraurban structures. 
The International Archives of the Photogrammetry, Remote Sensing and Spatial Information Sciences, Volume XLII-4/W12, 2019 5th International Conference on Geoinformation Science - GeoAdvances 2018, 10-11 October 2018, Casablanca, Morocco
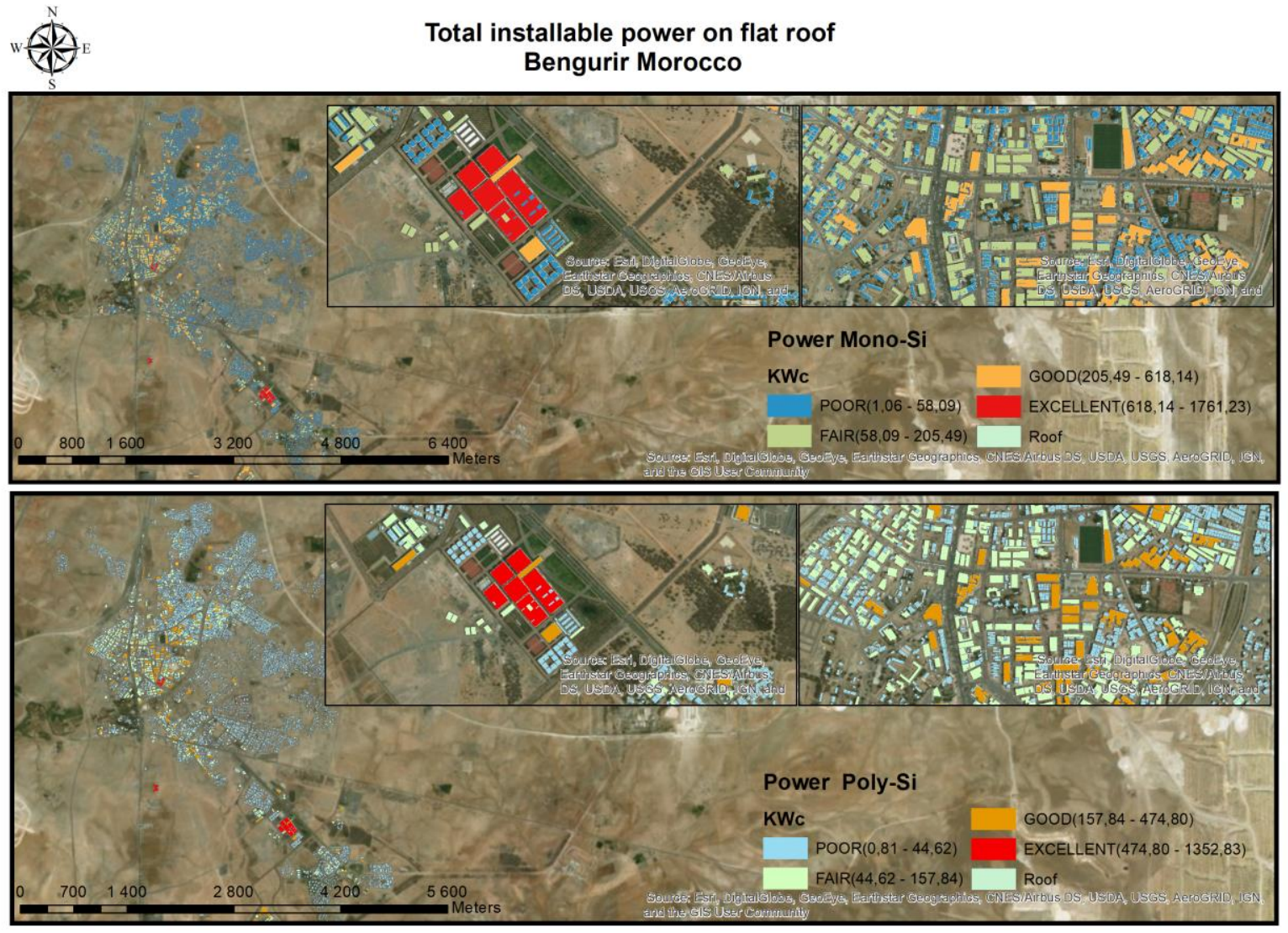

Figure 8. Total installable Power on flat roof
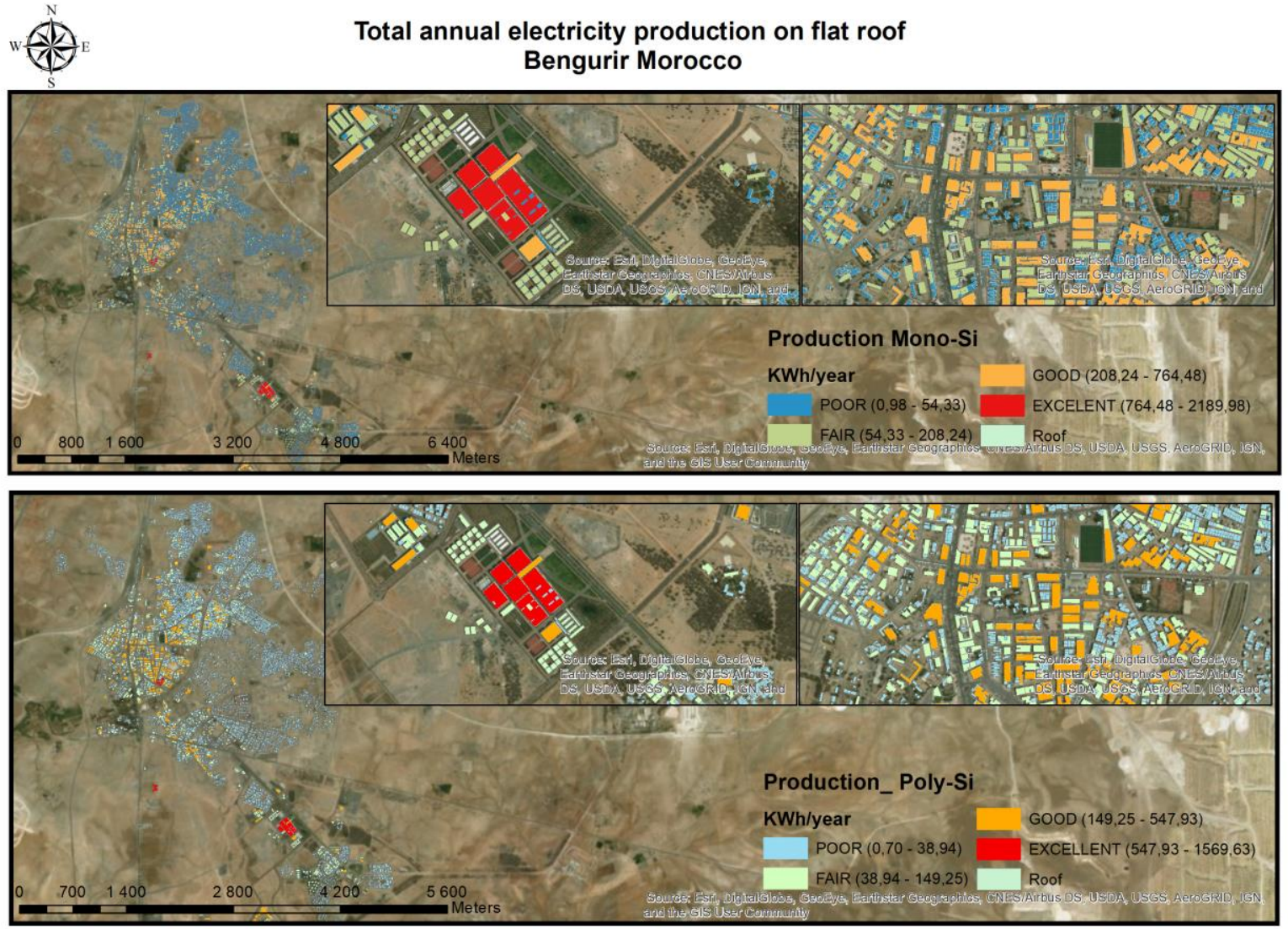

Figure 9. Total annual electricity production on flat roof 


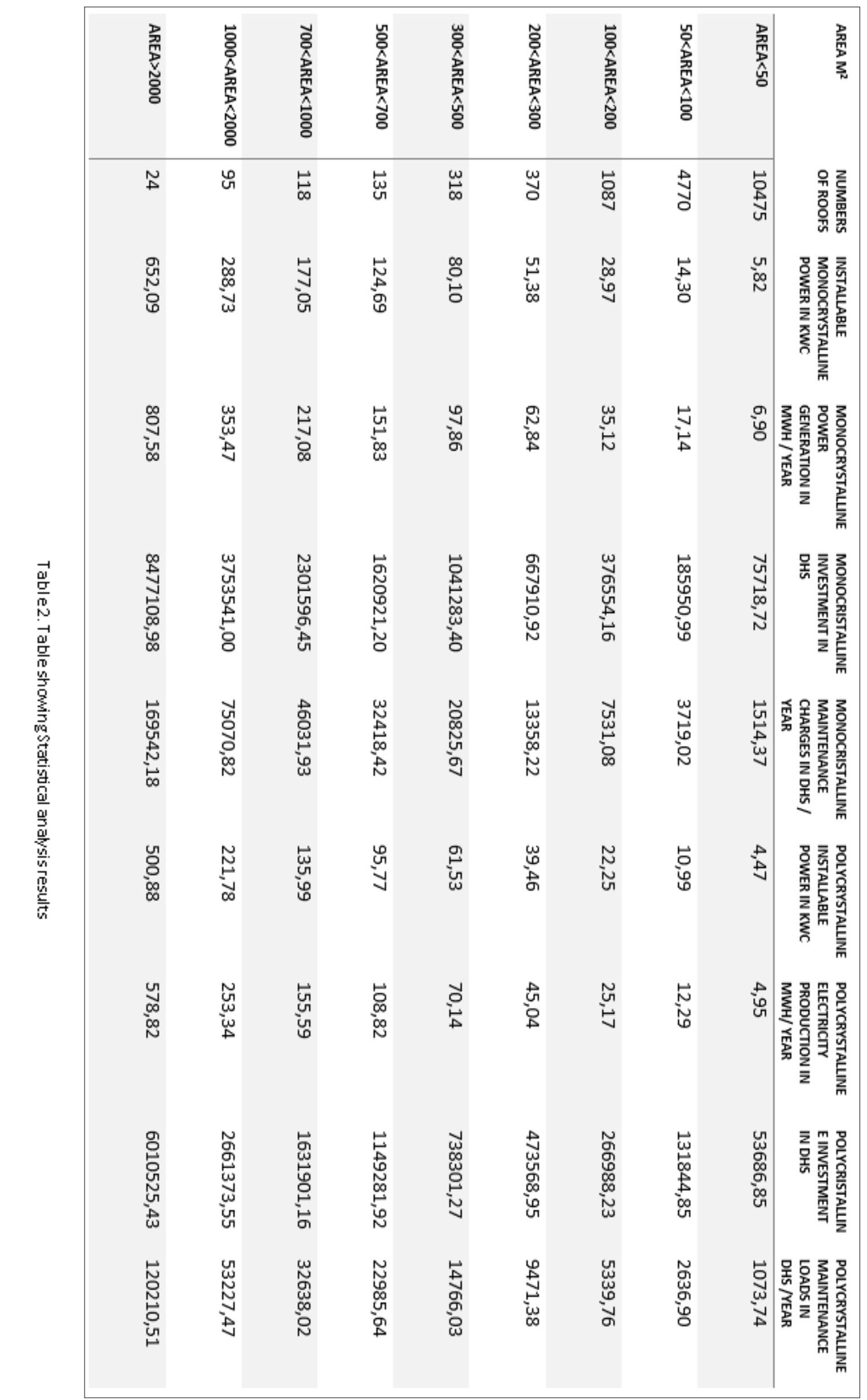




\section{ACKNOWLEDGMENT}

The authors wish to express their gratitude to the "Institut de Recherche en Energie Solaire et Energies Nouvelles" (IRESEN), the Green Energy Park Benguerir and the Kelaa-Sraghna Urban Agency, for their valuable advice and support. The authors also wish to thank all the teachers of the Department of Earth Sciences of the Ain Chock Faculty of Sciences of Hassan II University. Finally, the authors would like to thank all the teams who helped in this evaluation.

\section{REFERENCES}

D. Moser, D. Vettorato, R. Vaccaro, M. Del Buono, and W. Sparber, "The PV potential of south Tyrol: An intelligent use of space," Energy Procedia, vol. 57, no. December, pp. 1392-1400, 2014.

D. Moser, D. Vettorato, R. Vaccaro, M. Del Buono, and W. Sparber, "The PV potential of south Tyrol: An intelligent use of space,” Energy Procedia, vol. 57, pp. 1392-1400, 2014.

S. Freitas, C. Catita, P. Redweik, and M. C. Brito, "Modelling solar potential in the urban environment: State-of-the-art review," Renew. Sustain. Energy Rev., vol. 41, pp. 915-931, 2015.

K. Mainzer, K. Fath, R. Mckenna, J. Stengel, W. Fichtner, and F. Schultmann, "A high-resolution determination of the technical potential for residential-roof-mounted photovoltaic systems in Germany,” Sol. Energy, vol. 105, pp. 715-731, 2014.

D. Bressan, "D éveloppement d' un outil de supervision et de contr^ ole pour une installation solaire photovolta " 1 que To cite this version : Présentée par BRESSAN Michael Développement d ' un outil de supervision et de contrôle pour une installation solaire photo," 2014.

H. A. Effat and L. G. E. Taha, "GIS-Based Estimation of Potential Solar Energy on Flat Roofs in Maadi, Cairo, using True Ortho World View Image and Digital Surface Model," Int. J. Adv. Remote Sens. GIS, vol. 4, no. 1, pp. 1092-1108, 2015.

A. Chow, A. Fung, and S. Li, "GIS Modeling of Solar Neighborhood Potential at a Fine Spatiotemporal Resolution," Buildings, vol. 4, no. 2, pp. 195-206, 2014.

C. Delorme, C. Mohamed, and a. Otmani, "Détermination d'une irradiation solaire journalière à partir de trois irradiations horaires à 9, 12 et 15 h," Rev. Phys. Appliquée, vol. 24, no. 11, pp. 10231027,1989

Black and Veatch and Clean Power Research, "San Diego Distributed Solar Photovoltaics Impact Study,” 2014.

HEPPIA, "CADASTRE SOLAIRE DU CANTON DE GENEVE Phase 2 Analyse du potentiel de production énergétique par les panneaux solaires thermique et PV Rapport final,” p. 56, 2014.

A. Gastli and Y. Charabi, "Solar electricity prospects in Oman using GIS-based solar radiation maps," Renew. Sustain. Energy Rev., vol. 14, no. 2, pp. 790-797, 2010.

Y. Choi, J. Rayl, C. Tammineedi, and J. R. S. Brownson, "PV Analyst: Coupling ArcGIS with TRNSYS to assess distributed photovoltaic potential in urban areas," Sol. Energy, vol. 85, no. 11, pp. 2924-2939, 2011.
M. Uyan, "GIS-based solar farms site selection using analytic hierarchy process (AHP) in Karapinar region Konya/Turkey," Renew. Sustain. Energy Rev., vol. 28, pp. 11-17, 2013.

J. R. Janke, "Multicriteria GIS modeling of wind and solar farms in Colorado," Renew. Energy, vol. 35, no. 10, pp. 2228-2234, 2010.

P. Redweik, C. Catita, and M. Brito, "Solar energy potential on roofs and facades in an urban landscape," Sol. Energy, vol. 97, pp. 332-341, 2013.

L. Bergamasco and P. Asinari, "Scalable methodology for the photovoltaic solar energy potential assessment based on available roof surface area: Application to Piedmont Region (Italy)," Sol Energy, vol. 85, no. 5, pp. 1041-1055, 2011

T. R. Tooke, N. C. Coops, J. A. Voogt, and M. J. Meitner, "Tree structure influences on rooftop-received solar radiation," Landsc. Urban Plan., vol. 102, no. 2, pp. 73-81, 2011.

M. C. Brito, N. Gomes, T. Santos, and J. A. Tenedório, "Photovoltaic potential in a Lisbon suburb using LIDAR data," Sol. Energy, vol. 86, no. 1, pp. 283-288, 2012.

J. B. Kodysh, O. A. Omitaomu, B. L. Bhaduri, and B. S. Neish "Methodology for estimating solar potential on multiple building rooftops for photovoltaic systems," Sustain. Cities Soc., vol. 8, pp. $31-41,2013$.

S. M. Murshed, A. Simons, A. Lindsay, S. Picard, and C. De Pin, "Evaluation of Two Solar Radiation Algorithms on 3D City Models for Calculating Photovoltaic Potential," Proc. 4th Int Conf. Geogr. Inf. Syst. Theory, Appl. Manag., no. March, pp. 296303, 2018.

D. Assouline, N. Mohajeri, and J. L. Scartezzini, "Large-scale rooftop solar photovoltaic technical potential estimation using Random Forests," Appl. Energy, vol. 217, no. February, pp. 189$211,2018$.

D. Groppi, L. de Santoli, F. Cumo, and D. Astiaso Garcia, A GIS based model to assess buildings energy consumption and usable solar energy potential in urban areas, vol. 40, no. 2010. Elsevier B.V., 2018

A. Vulkan, I. Kloog, M. Dorman, and E. Erell, "Modeling the potential for PV installation in residential buildings in dense urban areas," Energy Build., vol. 169, pp. 97-109, 2018.

R. Buffat, S. Grassi, and M. Raubal, "A scalable method for estimating rooftop solar irradiation potential over large regions," Appl. Energy, vol. 216, no. February, pp. 389-401, 2018

W. Miller, A. Liu, Z. Amin, and A. Wagner, "Power quality and rooftop-photovoltaic households: An examination of measured data at point of customer connection," Sustain., vol. 10, no. 4, pp $1-27,2018$

M. Ntsoane, "Rooftop solar PV potential assessment in the city of Johannesburg," no. March, p. 61, 2017.

E. C. Kara, C. M. Roberts, M. Tabone, L. Alvarez, D. S. Callaway, and E. M. Stewart, "Towards Real-Time Estimation of Solar Generation From Micro-Synchrophasor Measurements," no. July, 2016. 
C. Carl, "Calculating Solar Photovoltaic Potential on Residential Rooftops in Kailua Kona, Hawaii,” no. May, pp. 1-83, 2014.

Integrated Solar Energy Generation Project, Kingdom of Morocco. Available online at 〈www.one.org.ma)

T. Santos, N. Gomes, S. Freire, M. C. Brito, L. Santos, and J. A. Tenedório, "Applications of solar mapping in the urban environment," Appl. Geogr., vol. 51, pp. 48-57, 2014. 